\title{
A simplified equation for two-dimensional drainage
}

\author{
C. Tzimopoulos, C. Evangelides \& G. Papaevangelou \\ Aristotle University of Thessaloniki, \\ Department of Rural and Surveying Engineering, Greece
}

\begin{abstract}
In this paper a new analytical solution for soil-water two-dimensional movement to an orthogonal mesh of parallel drains is presented, as an extended case of the one-dimensional flow problem of the same nature. An equation is provided that gives the profile of the water surface as well as the volume that has passed through the drains at a given time. A simplified form of the equation is presented, which provides very good results for time values higher than a certain level. Non-dimensional profiles of the piezometric surface are given for various values of time and space parameters. The water volume versus time derived from the respective equation accords well with the volume derived from surface profile integration.
\end{abstract}

Keywords: two-dimensional drainage, mathematical model, water profiles, drained volume.

\section{Introduction}

The flow of the subsurface water towards drains and ditches and the quantification of the respective drained volume as a function of time in cases of intense phenomena have considerable interest for land reclamation.

The problem reduces to the determination of the position of the watertable at the central point between successive drains as function of time. The purpose is to determine if a certain depth and a certain drain spacing satisfy design criteria, in relation to the lowering of the watertable after an intense irrigation or flood.

In the case of variable flow, Dumm [1] used a differential equation derived from the application of the continuity principle to describe the lowering of the watertable after its abrupt increase to a certain level over the drains. The solution 
describes the lowering of an initially horizontal watertable, as a function of time, space, drain spacing and soil properties. The analytical solution of an analogous equation of the one-dimensional problem in heat transfer was provided by Carlslaw and Jeager [2], and Luikov [3].

Many researchers gave similar solutions to the problem (Ritzema [4], McWhorter and Duke [5]). Freeze [6] developed a finite-difference model for the solution of the variable saturated-unsaturated flow. Dou et al. [7] presented a model of unstable flow in a confined aquifer, with results that converge to those of the analytical solution of Theis. An analytical solution for the total subsurface drained quantity in heavy soils was provided by Stibinger [8]. Numerical solutions of the two-dimensional variable free-surface flow to drains with finite difference schemes were provided by Todsen [9]. The case of the twodimensional drainage and more specifically of the lowering of the watertable was solved numerically with finite elements by Lagace et al. [10], and analytically for problems of stable drainage by Tzimopoulos and Sakellariou-Makrantonaki [11].

In the present article the two-dimensional case of this problem is approached analytically. Initially the full analytical solution of the problem is presented, which is followed by the simplification of the model, using only one of the terms of the numerical series of the full model. The precision of the results of the simplified model is examined as for the level of the water at the central point of the drain grid, as well as for the drained volume through time.

\section{The general model}

\subsection{The geometry}

A simple equation is presented here for the lowering of the watertable as well as for the remaining water volume, where a non-dimensional function is utilized, depending on $\mathrm{x}, \mathrm{y}$ and time, as described below. The geometry under study is shown in figure 1. Initially, the phreatic surface is considered horizontal. The height of the aquifer is $\mathrm{H}_{1}$ and the impermeable stratum is at a vertical distance $\mathrm{H}_{\mathrm{a}}$ under the drains. The distance between drains is $2 \mathrm{R}_{1}$ in the $\mathrm{x}$-direction and $2 \mathrm{R}_{2}$ in the $\mathrm{y}$-direction. The aquifer is considered unconfined, homogeneous and isotropic. The origin of the axes $\mathrm{x}$ and $\mathrm{y}$ is considered at the middle point of the drain spacing and the $\mathrm{z}$-axis is considered positive upwards.

The following assumptions are taken into account:

- The Dupuit assumption. The impervious subsoil is considered close to the drains, in order for this assumption to be valid.

- The unsaturated flow from the aeration zone to the saturated zone is negligible.

- There is no flow from rain or irrigation from the soil surface.

- The flow is horizontal, two-dimensional and symmetric.

With these assumptions, the time-dependent movement of the water towards the drains can be described by the well-known Boussinesq equation (Bear [12]): 


$$
\frac{\partial H}{\partial t}=\alpha\left(\frac{\partial^{2} H}{\partial x^{2}}+\frac{\partial^{2} H}{\partial y^{2}}\right) \quad \text { (1) } \quad \text { where: } \alpha=\frac{K \bar{H}}{S}
$$

with $H(x, y, t)=$ the height in $\mathrm{m}$ of the watertable from the impermeable stratum at the point $(x, y)$ at time moment $t, K$ the saturated hydraulic conductivity, $\mathrm{S}$ the storativity of the aquifer, $t$ the time after the beginning of the drainage, and $\bar{H}=\left(H_{1}+H_{a}\right) / 2$.
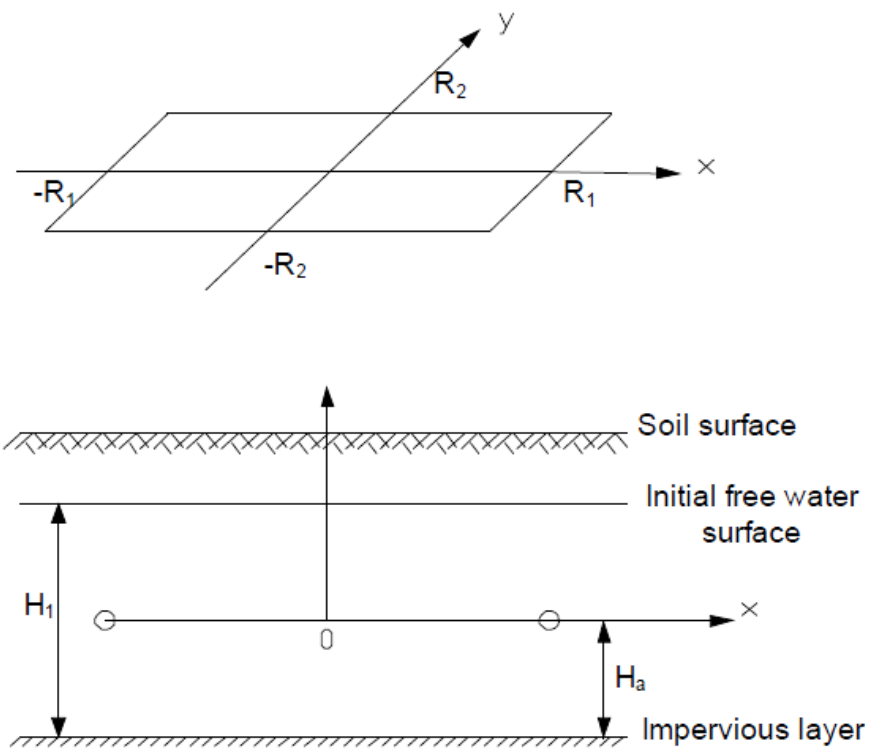

Figure 1: The geometry of the drainage problem.

\subsection{Initial and limit conditions and variable normalization}

It is considered that the initial shape of the aquifer at time point $\mathrm{t}=0$ (just before drainage $)$ is at level $\mathrm{H}(\mathrm{x}, \mathrm{y}, 0)=\mathrm{H}_{1}$.

As far as the limit conditions are concerned, for $x= \pm R_{1}$ it is: $H\left( \pm R_{1}, y, t\right)=$ $\mathrm{H}_{\mathrm{a}}$ and for $\mathrm{y}= \pm \mathrm{R}_{2}$ it is: $\mathrm{H}\left(\mathrm{x}, \pm \mathrm{R}_{2}, \mathrm{t}\right)=\mathrm{H}_{\mathrm{a}}$

By introducing the normalizing function:

$$
f(x, y, t)=\frac{H(x, y, t)-H_{\alpha}}{H_{1}-H_{\alpha}}
$$

the initial flow condition for $t=0$ becomes: $\quad f(x, y, t)=1$ and the limit conditions:

$$
\text { for } \mathrm{x}= \pm \mathrm{R}_{1} \text { it is: } \mathrm{f}\left( \pm \mathrm{R}_{1}, \mathrm{y}, \mathrm{t}\right)=0
$$

and for $y= \pm R_{2}: f\left(x, \pm R_{2}, t\right)=0$ 
For the case of this normalized solution, it is proven that:

$$
f(x, y, t)=f_{1}(x, t) f_{2}(y, t)=\frac{H-H_{\alpha}}{H_{1}-H_{\alpha}}=\frac{H(x, t)-H_{\alpha}}{H_{1}-H_{\alpha}} \frac{H(y, t)-H_{\alpha}}{H_{1}-H_{\alpha}}
$$

The above mentioned solution is analogous to the assumption of independence employed in probability theory, which reduces a joint probability density function to the product of its separate marginal density function and also analogous to the non-interactive fuzzy sets (Ross [13]).

Thus, eqn (4) consists of a solution of eqn (1).

\subsection{Analytical solution for the profile of the free surface}

For the one-dimensional case, it is proven $[2,3,11]$ that:

$$
\frac{H(x, t)-H_{\alpha}}{H_{1}-H_{\alpha}}=\sum_{n=1}^{\infty} \frac{2}{k_{n}} \cdot(-1)^{n+1} \cdot \cos \left(k_{n} \frac{2 x}{R_{1}}\right) \cdot e^{\left(-k_{n}^{2}\right)\left(\frac{\alpha \cdot t}{\mathrm{R}_{1}^{2}}\right)}
$$

where:

$$
k_{n}=(2 n-1) \cdot \frac{\pi}{2}
$$

which leads to the relationship:

$$
\frac{H(x, t)-H_{\alpha}}{H_{1}-H_{\alpha}}=\left(\frac{4}{\pi}\right) \cdot \sum_{n=0}^{\infty} \frac{(-1)^{n}}{2 n+1} \cdot \cos \frac{(2 n+1) \pi x}{2 R_{1}} \cdot e^{-a(2 n+1)^{2} \cdot \pi^{2} \cdot\left(t / 4 R_{1}^{2}\right)}
$$

Correspondingly for the y-direction:

$$
\frac{H(y, t)-H_{\alpha}}{H_{1}-H_{\alpha}}=\left(\frac{4}{\pi}\right) \cdot \sum_{m=0}^{\infty} \frac{(-1)^{m}}{2 m+1} \cdot \cos \frac{(2 m+1) \pi y}{2 R_{2}} \cdot e^{-a(2 m+1)^{2} \cdot \pi^{2} \cdot\left(t / 4 R_{2}^{2}\right)}
$$

and the total solution for the two-dimensional problem becomes:

$$
\begin{aligned}
& \frac{H(x, y, t)-H_{\alpha}}{H_{1}-H_{\alpha}}=\left(\frac{4}{\pi}\right)^{2} \cdot \sum_{n=0}^{\infty} \sum_{m=0}^{\infty} \frac{(-1)^{n}}{2 n+1} \cdot \frac{(-1)^{m}}{2 m+1} \cdot \cos \frac{(2 n+1) \pi x}{2 R_{1}} . \\
& \cos \frac{(2 m+1) \pi y}{2 R_{2}} \cdot e^{-a \cdot \frac{\pi^{2} t}{4} \cdot\left[\frac{(2 n+1)^{2}}{R_{1}^{2}}+\frac{(2 m+1)^{2}}{R_{21}^{2}}\right]}
\end{aligned}
$$

This solution satisfies the initial and the limit conditions of the problem.

\subsection{The drained volume}

The volume between the impermeable stratum and the free surface is given by:

$$
\begin{aligned}
& V=\iint H(x, y, t) d x d y=4 R_{1} R_{2} H_{\alpha}+ \\
& 4 R_{1} R_{2} \Delta H\left(\frac{4}{\pi}\right)^{2} \frac{1}{\pi^{2}} \sum_{n=0}^{\infty} \sum_{m=0}^{\infty} \frac{1}{(2 n+1)^{2}} \frac{1}{(2 m+1)^{2}} e^{-k_{1} t}
\end{aligned}
$$




$$
\text { with } k_{1}=\frac{a \cdot \pi^{2}}{4} \cdot\left(\frac{(2 n+1)^{2}}{R_{1}^{2}}+\frac{(2 m+1)^{2}}{R_{2}^{2}}\right)
$$

The volume of the water that has passed through the drains at a given time moment is then:

$$
V_{\text {out }}=4 R_{1} R_{2} \Delta H\left(1-\frac{4^{3}}{\pi^{4}} \sum_{n=0}^{\infty} \sum_{m=0}^{\infty} \frac{1}{(2 n+1)^{2}} e^{-\frac{\alpha \pi^{2} t(2 n+1)^{2}}{4 R_{1}^{2}}} \frac{1}{(2 m+1)^{2}} e^{-\frac{\alpha \pi^{2} t(2 m+1)^{2}}{4 R_{2}^{2}}}\right)
$$

where $\Delta \mathrm{H}=\mathrm{H}_{1}-\mathrm{H}_{\alpha}$.

For $\mathrm{t}=0$, it is $\mathrm{V}_{\text {out }}=0$, and for time $\mathrm{t}$ which tends to infinity it is $\mathrm{V}_{\text {out }}=4 \mathrm{R}_{1} \mathrm{R}_{2} \Delta H$.

\subsection{Results of the general model}

A program was developed in FORTRAN for the calculation of the threedimensional profile of the free water surface. This program allows the input of the space parameters $\mathrm{R}_{1}$ and $\lambda=\mathrm{R}_{1} / \mathrm{R}_{2}$, as well as of the non-dimensional parameter

$$
F_{0}=\frac{\alpha \cdot t}{R_{1}^{2}}
$$

where $\alpha$ was defined by eq (2). The parameters $R_{1}$ and $R_{2}$ are, as mentioned before, the spacings of the drains in the directions $\mathrm{x}$ and $\mathrm{y}$ respectively.

The program calculates the ratio: from eqn (9), as a function of $\xi=\frac{x}{2 R_{1}}$ and $\eta=\frac{y}{2 R_{1}}$, which are non-dimensional space parameters and results to the head $\mathrm{H}\left(\xi, \eta, \mathrm{F}_{0}\right)$ (figure 2 ). The parameters $\xi$ and $\eta$ are varied from 0.01 to 1 with a step of 0.01 .

As appears in figure 2, the profiles present instabilities at the lower values of the time parameter $F_{0}$ (at these time values the drainage influences mainly the area close to the drains, resulting in values of the non-dimensional head around unity). In figures 2 and 3 , the profiles for $F_{0}=0.01$ and $F_{0}=0.1$ are shown for $\lambda=1$ and 2 , in two and three dimensions respectively, $\lambda$ being the ratio of the drain spacing in the two directions: $\lambda=\mathrm{R}_{1} / \mathrm{R}_{2}$.

\section{The simplified model}

The maximum value of the head of the watertable occurs at the central point of the grid, that is, at point $(x, y)=(0,0)$. This head is given by:

$$
\frac{H(0,0, t)-H_{\alpha}}{H_{1}-H_{a}}=\left(\frac{4}{\pi}\right)^{2} \cdot \sum_{n=0}^{\infty}\left(\frac{(-1)^{n}}{2 n+1} \cdot e^{-\frac{\alpha \pi^{2} t}{4 R_{1}^{2}}(2 n+1)^{2}}\right) \sum_{m=0}^{\infty}\left(\frac{(-1)^{m}}{2 m+1} \cdot e^{-\frac{\alpha \pi^{2} t}{4 R_{2}{ }^{2}}(2 m+1)^{2}}\right)
$$



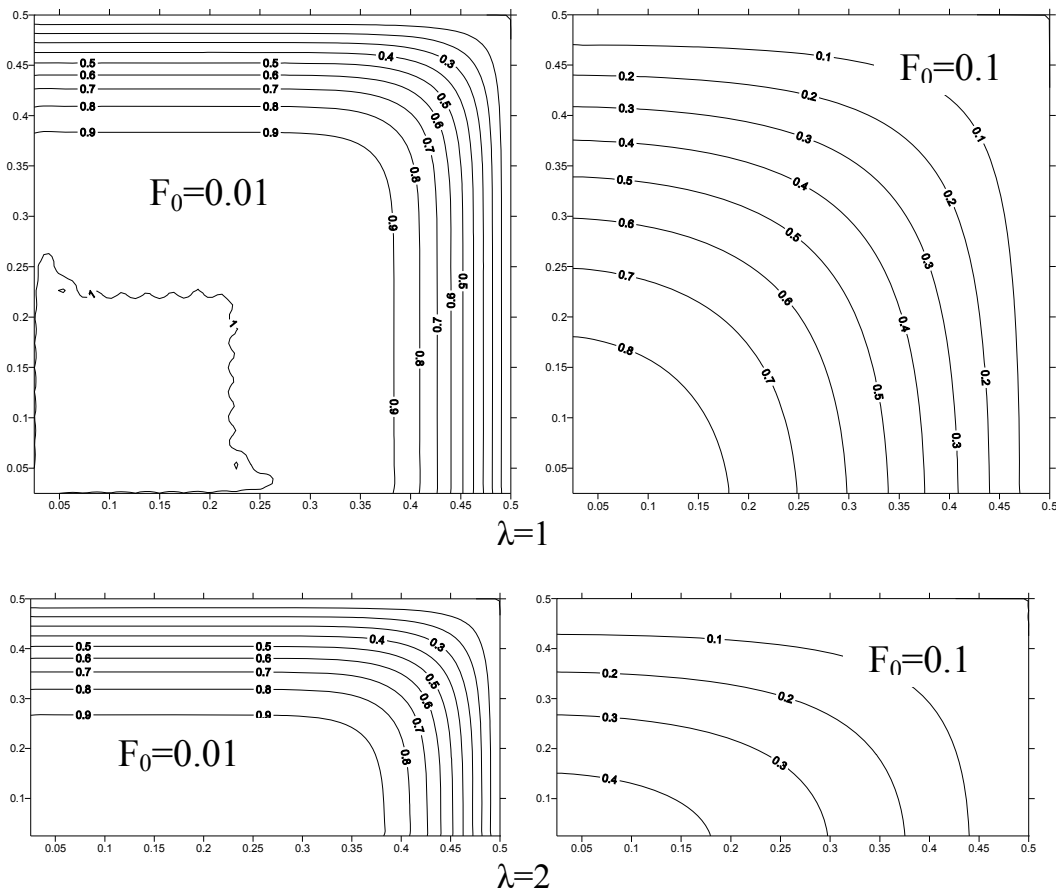

Figure 2: Non-dimensional profiles for values of the time parameter $\mathrm{F}_{0}=10^{-2}$ and $10^{-1}$ and for $\lambda=1$ and 2 .

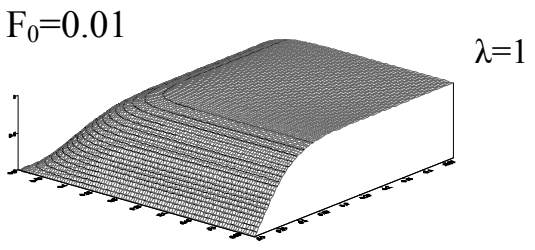

$$
\mathrm{F}_{0}=0.1
$$

$\lambda=2$
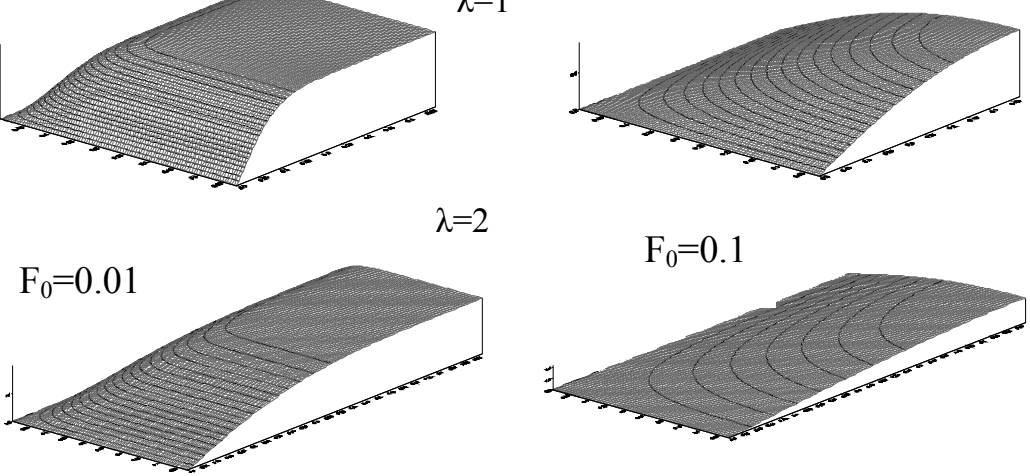

Figure 3: Three-dimensional profiles for two time-points and two geometries. 
It is easily shown that the terms of the series of this equation after the third one, are practically zero. In a simplified version of the mathematical model, we used only the first term from each series. This simplified model results for the head at the central point to:

$$
\frac{H(0,0, t)-H_{\alpha}}{H_{1}-H_{a}}=\left(\frac{4}{\pi}\right)^{2} \cdot e^{-\frac{\pi^{2} F_{0}\left(\lambda^{2}+1\right)}{4}}
$$

Eqn (15) provides the water head as a function of the drain spacings in the $\mathrm{x}$ and y-directions. In figure 4, this head is shown as it is derived from the general model, as well as from the simplified one. For high values of the time parameter $\mathrm{F}_{0}$, the results of the two models coincide. For low values of this parameter, that is for $\mathrm{F}_{0}<0.3$, the simplified model overestimates the water head.

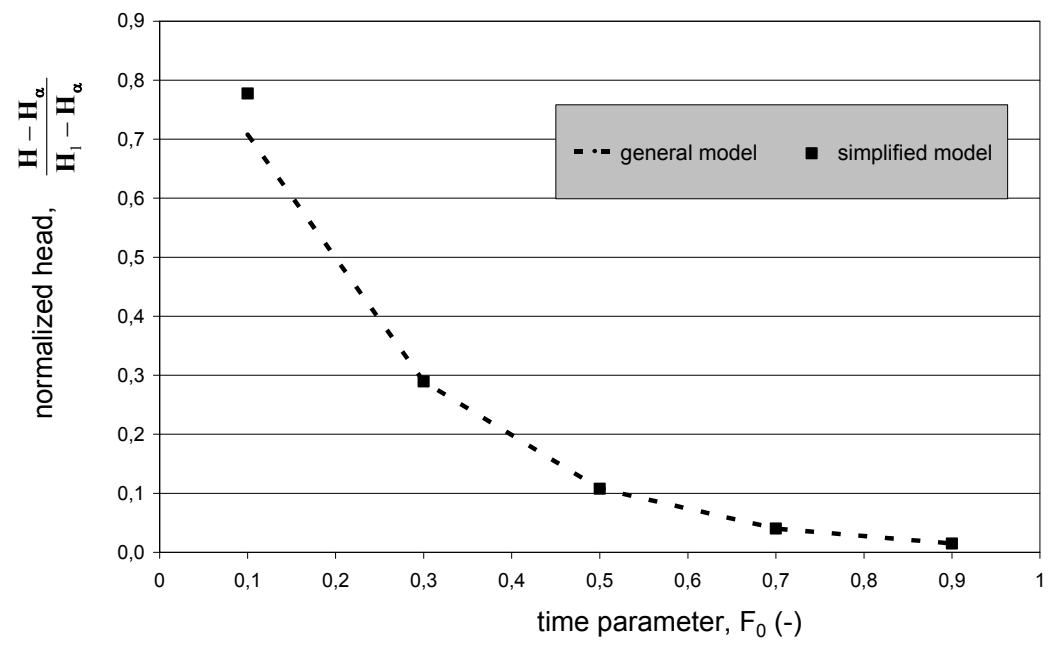

Figure 4: $\quad$ Normalized head derived from the general and from the simplified model.

The drained water volume as a function of time in the general model was proven above to be:

$$
V_{\text {out }}=4 R_{1} R_{2} \Delta H\left(1-\frac{4^{3}}{\pi^{4}} \sum_{n=0}^{\infty} \sum_{m=0}^{\infty} \frac{1}{(2 n+1)^{2}} e^{-\frac{\alpha \pi^{2} t(2 n+1)^{2}}{4 R_{1}^{2}}} \frac{1}{(2 m+1)^{2}} e^{-\frac{\alpha \pi^{2} t(2 m+1)^{2}}{4 R_{2}^{2}}}\right)
$$

The values of this volume as determined by this analytical expression are compared in figure 5 with the ones that were derived from the numerical integration of the surfaces described in the previous paragraph: 


$$
V=V_{\text {tot }}-\int_{x \min }^{x \max y} \int_{y \min }^{\max } f(x, y) d x d y
$$

In the simplified model, that is, considering only the first term of the summations, in the case of a square drain network, the drained volume at a given time moment $t$, is given by the simplification of eqn (16):

$$
\frac{V_{\text {out }}}{V_{\text {tot }}}=1-\frac{64}{\pi^{4}} \cdot e^{-\frac{\pi^{2} F_{0}}{2}}
$$

The drained volume, as estimated by the simplified model, is also shown in figure 5 and presents a very good agreement with the one of the general model for $\mathrm{F}_{0}>0.1$. As in the case of the head, the simplified model diverts from the general one for time values near the beginning of the drainage, though it converges with the general model for high time values.

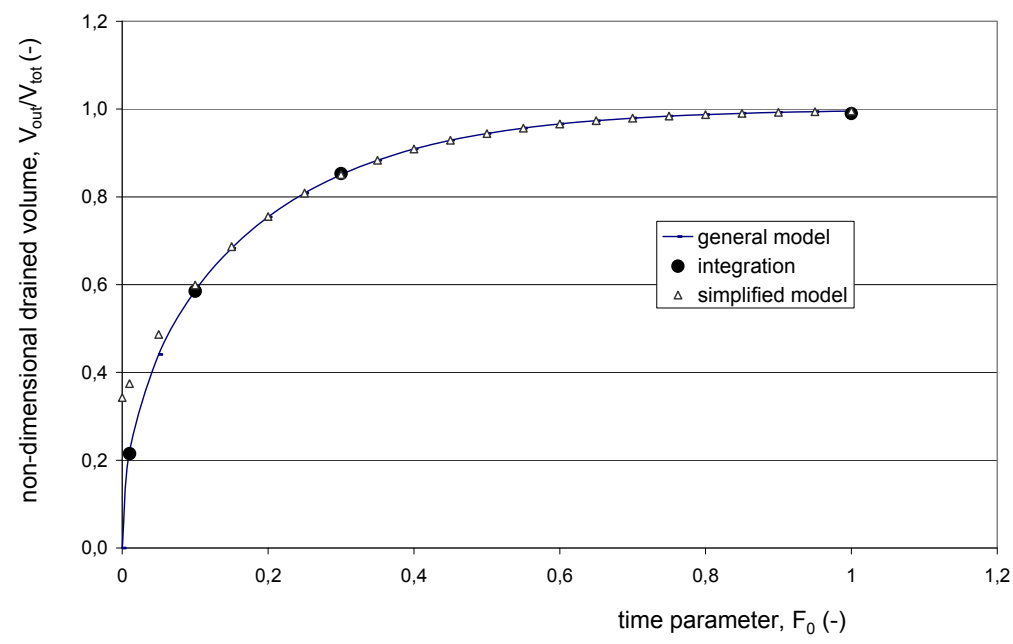

Figure 5: Non-dimensional drained volume versus time parameter $\mathrm{F}_{0}$.

For a better estimation of the number of terms that are necessary in the summation series of the model, it was checked after how many terms the sum

$$
\sum_{n=0}^{30} \frac{(-1)^{n}}{2 n+1} e^{-\frac{\pi}{4} F_{0}(2 n+1)^{2}}
$$

converges to its final value, as a function of the parameter $\mathrm{F}_{0}$. As seen in figure 6 , in which the $\mathrm{x}$-axis is the number of terms, for $\mathrm{F}_{0}>0.25$, there is no need for terms higher than the second one, and thus, the simplified model provides results that coincide with those of the general. This means that for time values after the first hours of the intensive phenomenon of flood or irrigation, the simplified 
model described here by eqns (15) and (18), gives excellent results. Of course, as derived from figure 6 , one needs about 6 terms in eqns (9) and (11) of the general model in order to be accurate, in cases where the first time period is of major interest.

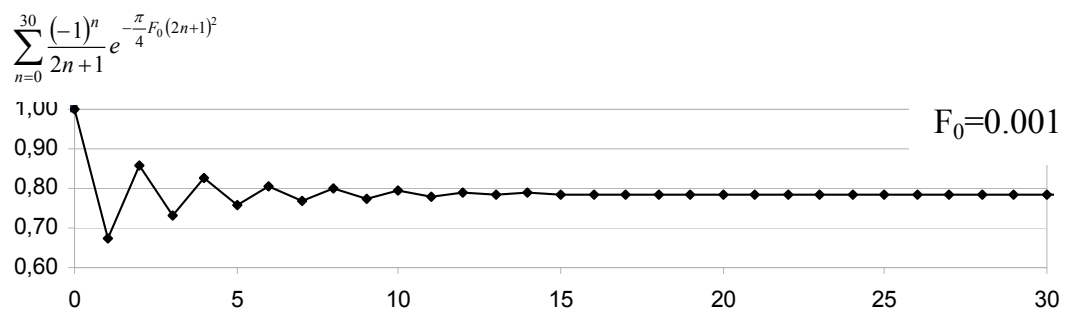

Number of terms of the summation
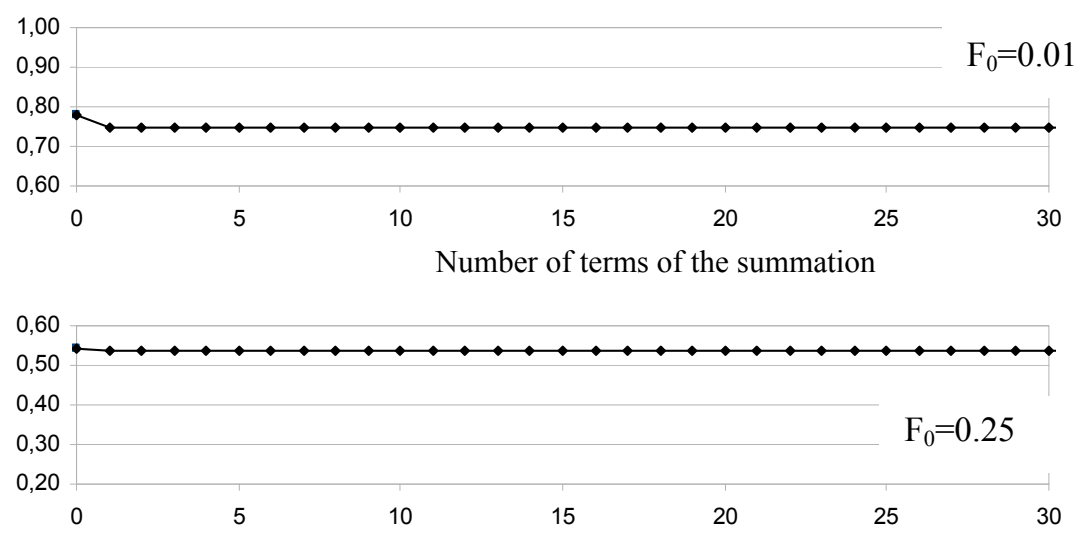

Figure 6: The value of the summation of the general model.

\section{Conclusion}

The simplified mathematical model that was presented in the present paper for the free surface of the water and for the drained volume in the case of the twodimensional drainage after heavy rain or irrigation, showed very good results in comparison with those of a general model for the same drainage case that has been presented in this paper.

The simplified model provides results that practically coincide with those of the general, for time values higher than the initial $20 \%$ of the total drainage time. Given that the knowledge of the water profile for times after the first hours that follow an intensive rain or irrigation is important for many issues of drainage, it is believed that such a model would help in the estimation of the water head and volume. 


\section{References}

[1] Dumm, L.D., Drain Spacing Formula, Agricultural Engineering, 35, pp. 726-730, 1954.

[2] Carlslaw, H.S., Jaeger J.C., Conduction of heat in Solids, Oxford Clarendon Press: Oxford, pp.510, 1982.

[3] Luikov A.D., Analytical Heat Diffusion Theory, Academic Press, pp. 685, 1968.

[4] Ritzema, H.P., Drainage principles and Applications, International Institute for Land Reclamation and Improvement, pp. 1125pp, 1994.

[5] McWhorter, D.B., Duke, H.R., Transient Drainage with Nonlinearity and Capillarity, Journal of the Irrigation and Drainage Division, 102(2), pp. 193-204, 1976.

[6] Freeze, R.A., Three-Dimensional. Transient. Saturated-Unsaturated Flow in a Groundwater basin, Water Resources Research, 7(2), pp. 347-366, 1971.

[7] Dou, C., Woldt, W., Dahab, M. and Bogardi, I., Transient Ground-Water Flow Simulation Using a Fuzzy Set Approach, Groundwater, 35, pp. 205215, 1997.

[8] Stibinger, 2003, Analytical approximation of subsurface total drainage quantity in non-steady state drainage flow, and its verification in heavy soils, Irrigation and Drainage Systems, 17 pp. 341-365, 2003.

[9] Todsen M., Numerical Studies of two-Dimensional Saturated/Unsaturated Drainage Models, Journal of Hydrology, 20, pp. 311-326, 1973.

[10] Lagace, R., Skaggs, R.W., Parsons, J.E., Predicting water table drawdown for two-dimensional drainage, Advances in Drainage, Proceedings of the ASAE, Fourth National Drainage Symposium, pp.6-15, 1982.

[11] Tzimopoulos C, Sakellariou-Makrantonaki M., Water table drawdown for two-dimensional drainage, Advances in Water Resources, 10(3), pp. 158163, 1987.

[12] Bear, J., Dynamics of Fluids in Porous Media, Dover Publications: New York, pp.764, 1972.

[13] Ross, T. J., Fuzzy Logic with Engineering Applications, John Wiley \& Sons Ltd, pp. 628, 2004. 